
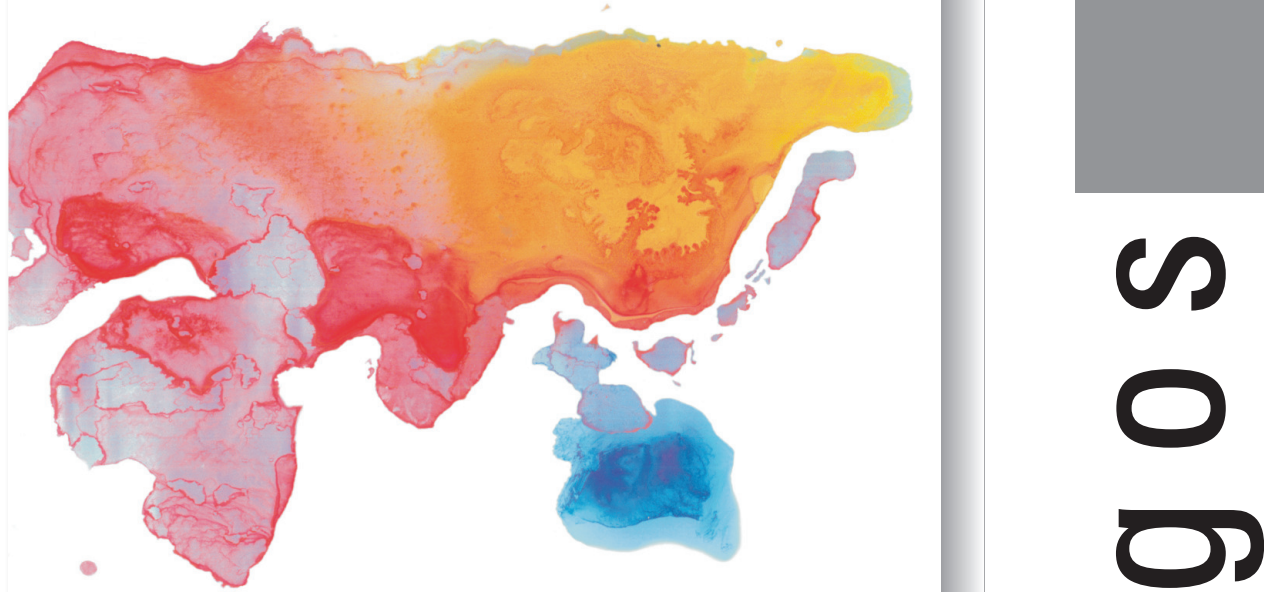

$\square$
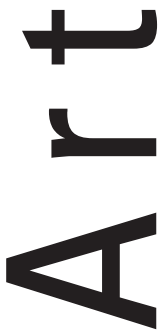


\title{
Territórios e territorialidades urbanas em Goiânia: as tribos dos moto clubes
}

\author{
Territories and urban territorialities in Goiania: the tribes of the motorcycle clubs \\ Maria Elisabeth Alves Mesquita - IESA/UFG \\ geoelisabeth@gmail.com \\ Carlos Eduardo Santos Maia - IESA/UFG \\ carlmaia@uol.com.br
}

\begin{abstract}
Resumo
0 intuito deste trabalho é analisar as tribos urbanas, fenômenos contemporâneos, a partir das categorias território e territorialidade. Na tentativa de ampliar a visão sobre tal assunto, de inegável importância na atualidade, busca-se demonstrar como estas se organizam espacialmente e como se dá a sua dinâmica organizacional e inter-relação com o espaço citadino, tomando-se o exemplo dos moto clubes da cidade de Goiânia - GO. Acerca deste caso específico, investigaremos sobre os modos como os membros dos moto clubes goianienses se relacionam com as atividades de comércio e lazer da cidade mas, ao mesmo tempo, criam fronteiras em espaços sociais tidos como públicos, controlando o seu acesso. Assim, notar-se-ão territórios que são firmados em códigos simbólicos, comportamentais e identitários de cada tribo no seu "pedaço".
\end{abstract}

Palavras-chave: território, territorialidade urbana, tribos urbanas e moto clubes

\begin{abstract}
The intention of this work is to analyze the urban tribes, phenomena contemporaries, from the categories territory and territoriality. In the attempt to extend the vision on such subject, of undeniable importance in the present time, one searchs to demonstrate as these if they organize space and as if it gives to its organizacional dynamics and interrelation with the space city dweller, being overcome the example of the motorcycles clubs of the city of Goiânia - GO. Concerning this in case that specific, we will invest on the ways as the members of the motion goianienses clubs if they relate with the activities of commerce and leisure of the city but, at the same time, they create borders in had social spaces as public, controlling its access. Thus, territories that are firmed in symbolic codes, mannering and identitários will be noticed of each tribe in its "piece".
\end{abstract}

Key-words: territory, urban territoriality, urban tribes e motorcycle clubs

\begin{tabular}{|l|c|c|c|c|c|c|}
\hline Boletim Goiano de Geografia & Goiânia - Goiás - Brasil & v. 27 & n. 3 & p. 125-142 & jul. / dez. & 2007 \\
\hline
\end{tabular}





\section{Ligando os motores}

Nesta pesquisa, busca-se contribuir com uma possível interpretação para determinados aspectos relativos à espacialidade dos moto clubes da cidade de Goiânia. Moto clubes são organizações formadas, em sua maioria, por homens que possuem como bem comum a motocicleta. Afora o mero sentido de locomoção, esses motociclistas cultivam um ideal de liberdade e aventura que é proporcionado pelo veículo, costumeiramente materializado em longas viagens, previamente agendadas, chegando a ultrapassar as fronteiras brasileiras.

Os membros de moto clubes que, por questões de trabalho, não fazem essas viagens de longos percursos podem ser vistos nos encontros de motociclistas, nas sedes das entidades, nos moto bares e nas comemorações festivas (como aniversários) e eventos que acontecem durante todo o ano em Goiânia. Essas organizações são registradas em cartório, possuem estatuto e características diferenciadas entre si, de modo que, atualmente, têm-se contabilizado trinta e nove moto clubes em Goiânia, mas já existiram sessenta e dois.

Ressalte-se que, atualmente, o maior diálogo entre as ciências e a complexidade da dinâmica social clama por múltiplos olhares, estando a geografia atenta a esses gritos com enfoques plurais. Desse modo, nas páginas seguintes, questiona-se o fenômeno das tribos urbanas com um discurso transdisciplinar, mas costurado pelos conceitos de território e territorialidade. Toma-se a cidade de Goiana enquanto recorte espacial, pois aí se constituem, como noutras metrópoles, apesar dos rótulos de cidade country, capital sertaneja ou ainda da qualificação idílica de cidade das flores.

Perseguindo nosso objetivo, tomaremos, inicialmente, o caminho do debate teórico sobre o tribalismo contemporâneo para, a seguir, trafegarmos pelos movimentos de contracultura e tribos urbanas com vistas a desbravaremos os pedaços territorializados pelos motoclubes.

\section{Com o pé na estrada: do individualismo para o tribalismo contemporâneo}

O conceito de tribo tem seu domínio original na etnologia, sendo utilizado para definir uma forma de organização da sociedade, especialmente as indígenas, pela antropologia. Para Magnani (1992), pode-se dizer que tribo constitui uma forma de organização mais ampla, que vai além das divisões de clã ou linhagem, de um lado, e da aldeia, de outro. Trata-se de um pacto 
que aciona lealdades, que extrapola os particularismos de grupos domésticos e locais. Porém, o tribalismo aqui tratado possui outra conotação e se manifesta em espaços diferentes destes comentados.

Em se tratando de tribalismo no mundo contemporâneo e de novos modos de organização social, faz-se imprescindível o seguinte recorte espaço-temporal, a fim de decifrar em quais sociedades eclodiram esse fenômeno e quando: o urbano, em especial as cidades industriais ou centros de gestão financeira, de porte médio e grande, que hoje são chamadas de metrópoles nacionais e mundiais. "A grande metrópole contemporânea é, portanto, a expressão aguda e nítida desse modo de vida, o lócus, por excelência, das realizações e traços mais característicos desse novo tipo de sociedade" (VELHO, 1987, p. 17).

Mas o tribalismo nos faz pensar também em sua antítese: o individualismo. Em termos antropológicos, individualismo "é qualquer cultura onde o indivíduo tem um valor superior ao grupo, o termo individualismo aqui não tem uma conotação moral, no sentido em que usamos normalmente, como sinônimo de egoísmo" (CALIGARIS, 2003, p.3). Ao fazer um resgate histórico do individualismo, Maffesoli (2004) afirma que o período de reforma religiosa proposta por Lutero e Calvino foi essencial para a propagação deste ideário, introduzindo naquela época a noção de livre-arbítrio e a expressão de uma relação individual que um "eu" iria estabelecer com uma alteridade absoluta. Esta noção foi igualmente constatada na Revolução Francesa e no código napoleônico, onde se postula que a partir do indivíduo relacional é estabelecido um contrato social. Outra expressão que atesta essas concepções iniciais do individualismo é a autonomia ou individuo autônomo, ambas presentes em Descartes, na reforma e no iluminismo. Maffesoli observa que a idéia do eu sou a minha própria lei foi o pivô da modernidade, enfatizando essa concepção do indivíduo que dá a sua lei a si mesmo e que, em seguida, pode se associar a outros indivíduos autônomos para fazer a história. A partir daí, se constrói o contrato social. No Brasil, um caso exemplar de exaltação deste indivíduo foi consignado na lei de Gerson, nos anos setenta, amplamente divulgada na mídia, que preconizava que o importante é fazer a sua própria lei e tirar vantagem em tudo. $\mathrm{O}$ individualismo, então, é uma expressão social específica da modernidade.

Para Velho (1987), não existem projetos individuais puros, ou seja, sem referência, isto quer dizer que o individualismo não é um fenômeno puramente interno, subjetivo. Formula-se e é elaborado dentro de um campo de possibilidades, circunscrito historicamente e culturalmente, tanto em 
termos da própria noção de indivíduo como dos temas, prioridades e paradigmas culturais existentes. Nessa perspectiva, quanto mais exposto estiver o sujeito a experiências diversificadas, quanto mais tiver de dar conta do ethos e visões de mundo contrastantes, quanto menos fechada for sua rede de relação cotidiana, mais marcada será a sua autopercepção de individualidade singular. Há que se considerar que se está mais sujeito a isso nas grandes cidades contemporâneas do que em sociedades de pequena escala em virtude das possíveis invasões de seus mundos e das irrupções e crises ocasionadas pela proximidade física e social com outros estilos de vida e definições de realidade.

Cardoza (2003) complementa, observando a relação entre um sujeito que não tem mais domínio sobre as limitações de si e o sistema coletivo a que ele se integra, o qual lhe envolve a ponto de tornar-lhe inconsciente de sua própria atuação social. A autora retoma a teoria psicanalítica do inconsciente do século XIX, que causou uma onda de racionalização no homem, dizendo que o homem não poderia ser conhecedor e senhor de suas atribuições, pois, como parte pertencente de seu psiquismo, estava um inconsciente, com caracterizações tão primitivas e tão próprias que nem mesmo este homem antropocêntrico poderia tomar-lhe as rédeas.

Tal como Velho (1987) que trata da inexistência de projetos individuais, Maffesoli recorre a este primado para tratar do tribalismo. O tribalismo não é um fenômeno específico, mas uma metáfora da pós-modernidade, em que as grandes bases sólidas de organização social, as instituições como família, religião e estado nação estão saturadas, ou mesmo, como diz Maffesoli, são "porosas". Tem-se a impressão de que se percebeu que as idéias não eram mais autônomas, pois foram criadas a partir de um coletivo, e esse coletivo está sendo questionado. A humanidade então vive um "período empático", em que predomina a diferenciação e o perder-se em um "sujeito coletivo". O autor comenta que o tribalismo, chamado também por ele de neotribalismo, deve ser tomado como um novo paradigma que substitui o do individualismo na compreensão da sociedade contemporânea, e continua: "Assistimos agora à passagem da identidade para as identificações múltiplas. É essa passagem que me parece fundar o nascimento de formas tribais de existência (...) Aqui, onde nós deveríamos pensar em nós mesmos, vemos constituir-se pequenas entidades sectárias, fanáticas, opondo-se umas às outras (MAFFESOLI , 2004, p.28)”.

Cardoza (2003) atesta que, desta forma, a pós-modernidade caracteriza-se por trazer consigo todas as mudanças culturais e sociais resultantes 
do triunfo do capitalismo sobre o socialismo real e do declínio de um individualismo hegemônico; da modernidade fundada na máxima da razão e nos princípios iluministas, o que é compartilhado por Maffesoli. Isto vem alterar a percepção da realidade do indivíduo, que é obrigado a redefinir suas práticas cotidianas e estar exposto às diferenciações de experiências a serem vivenciadas; acarretando o declínio das tradições e a acelerada pluralização de grupos primários - a chamada dessocialização causada pela cultura de massa, que resulta na constituição de um novo enfoque às subjetividades, promovendo novas noções de hábitos e valores.

Dando continuidade a essa explanação da saturação das instituições e da perda de evidências e valores, que tentam explicar a queda do individualismo e fixação do tribalismo, retomamos a Caligaris (2003) que atribui essa perda ao princípio do capitalismo de exaltar a predominância de sujeitos não definidos por suas origens, seus grupos, seus laços e suas histórias, tornando-se puros agentes econômicos, produtores e consumidores. Por um lado, nossa subjetividade, notavelmente rarefeita, continua assim porque tudo o que nos definia de maneira concreta (a origem, o sangue, a casta, o privilégio, as obrigações da história) não nos define mais. As tradições que regravam nossa vida, que fundavam as divisões em grupos de poder, são atacadas e recusadas. Paralelamente, espera-se que em nós mesmos enquanto indivíduos seja possível encontrar novos fundamentos para a convivência social, para não sermos regrados pelas mesmas tradições e cânones que então negamos.

Para Caligaris (2003), essa autodefinição de indivíduo é bastante abstrata, pois parte da premissa deste ser definido pelos grupos de pertencimento, chegando-se à busca da autenticidade, termo que se torna crucial, sobretudo nos últimos 200 anos. O autor exalta a idéia de a humanidade ter criado uma paixão pela autenticidade, ou seja, por aquele lugar onde seríamos únicos, diferentes e completamente nós mesmos.

Contudo, agora é visto que o capitalismo descobriu que o maior estímulo ao consumo é a nossa procura de autenticidade, a nossa consideração dos outros, pois só assim pode-se afirmar a autenticidade, ou seja, dependese do olhar dos outros. A diferença em nossa vida social é instituída pelo reconhecimento que vem dos outros. Aqui está o grande dilema das sociedades ocidentais contemporâneas: o sonho de uma sociedade de indivíduos e a necessidade de fragmentação social, para justamente cada um poder assim ser reconhecido pelo que ele é. Infere-se que estaríamos caminhando em direção à persona e à multiplicidade de papéis e máscaras a pessoa só existe 
em termos do papel ou máscara usada em dado momento ou situação, como chama atenção Maffesoli (2004).

Nessa perspectiva de existir como sujeito identitário em função de um grupo social, vimos que, em especial, o homem cuja vida é predominantemente urbana, está mais sujeito à absorver e criar novas identidades, ou, como afirma Amaral "é um homem multifacetado" (1992, p. 46). Simmel, de modo complementar, exara: "Sua noção de pessoa é constituída pela soma dos efeitos que dela emana temporal e espacialmente” (1987, p.21). Mesmo que as bases econômicas e forças globalizadoras nos transmitam a idéia de um ser uniformizado, universalista, essa idéia é aparente, "se a cidade atual parece apresentar uma sociedade sem estilo é justamente porque sua feição é a somatória dos estilos dos grupos que vivem nela" (1992, p. 35).

Somando outras a essas explicações sobre o fenômeno tribal, temos Takeuti (2004), que evidencia esse acontecimento na sociedade juvenil, mas traz observações pertinentes para tal escolha de viver em grupo em termos gerais, ou seja, nas demais faixas etárias. Takeuti atribui o tribalismo à ineficácia simbólica existente na sociedade. Essa sugestão não vem discordar dos autores citados anteriormente, mas sim complementar a idéia sobre a perda de evidências. Nota-se que, a precariedade simbólica consistente, em que se disponibilizam os modelos identitários, é fruto da valorização radicalizada da dimensão econômica e sua prevalência enquanto significação imaginária social causadora da aniquilação de valores que poderiam trazer outros sentidos de vida aos indivíduos.

Não se pode relegar o limite do vazio, fato notório nas sociedades industrializadas, o que para Bertaux (1988) revela-se como um estar em todos os lugares e ao mesmo tempo não se estar em parte alguma, no sentido efetivo de pertença. O indivíduo, desse modo, liberado de toda amarra, mas também desprovido de toda a individualidade, está pronto para se juntar a qualquer grupo, pronto a endossar a identidade que se queira bem lhe propor, ou seja, tudo menos o vazio.

Através de Caligaris (2003), Maffesoli (1944) (2004), Takeuti (2004), Velho (1987), Cardoza (2003) e Bertaux (1988) tem-se a caracterização da situação pós-moderna, na qual o tribal surge como uma espécie de compensação diante de uma sociedade cujos laços e coesão social são frágeis. Reencantamento pelo mundo é o termo usado por Quaresma (2006) para definir essa situação, ou seja, o fenômeno neotribal traz uma possibilidade de reencantamento, tendo como cimento principal uma emoção ou sensibilidade vivida em comum. O período pós-moderno demonstra que os homens estariam adotando um ponto de vista mais emotivo em relação ao mundo. 
Max Weber já fazia observações sobre esses laços quando se referia às comunidades afetivas ou emocionais, termo também utilizado por Mafessoli (2004) em relação ao homo estheticus, "base do tribalismo", na visão do autor, já que se constitui nas "emoções compartilhadas".

Para Quaresma (2006), essa proposta de Maffesoli traz mesmo um novo paradigma de compreensão da sociedade contemporânea, que está baseado na necessidade de solidariedade e de proteção característicos do conjunto social. Desta forma, a metáfora tribo dará conta do processo de desindividualização e da valorização do papel que cada pessoa (persona) é chamada a representar dentro do grupo.

Dentre os diversos comportamentos sociais nascidos nesse momento, o de desencantamento pelo mundo sobressai principalmente entre os jovens, que deram origem à composição de tribos urbanas. Embora não se afirme ainda que os motociclistas de moto clubes são jovens, ou mesmo grupos juvenis, já foi percebido que o seu surgimento é uma resposta a esta sociedade que os deixou de fora. Também se reconhece que esses grupos não tencionam necessariamente o questionamento da ordem social, mas não deixam de ser uma reação à dificuldade de "entrar" neste modo de vida, ou seja, produzem uma resposta à condição social. Resgatemos, para esclarecer melhor isto, o que foi caracterizado como Movimentos de Contracultura.

Antes Sonhava, Hoje não Durmo: percorrendo os movimentos de contracultura e tribos urbanas

A contracultura foi um movimento que teve como endereço de origem os Estados Unidos e, como data característica, o pós-guerra, final da década de 40. Entendamos a situação estadonidense naquele contexto para que compreendamos melhor o porquê de certas circunstâncias sociais, econômicas e culturais terem propiciado o nascimento desse movimento naquela sociedade.

Marcuse (1982) observa que, existiu, imediatamente, no pós-guerra, uma ausência de agentes de transformação social na sociedade norte americana tecnologicamente desenvolvida, o que demonstrava um certo grau de alienação social. Criou-se a falsa idéia de que nada faltava ao homem que possuía um emprego, dinheiro para as necessidades imediatas, para bens de consumo duráveis e não duráveis, e ainda podia escolher seus futuros representantes, gerando a sensação de autonomia e liberdade. Foi naquela nova sociedade, de indivíduos reprimidos e submissos a uma cultura massificada, em que prevalecia a ilusão de progresso e liberdade, que vieram à tona protestos contra a própria pátria e seus falsos pais, falsos professores e falsos 
heróis; movimentos que foram minados pela sua imaturidade, apolitização e sugados pelos meios de comunicação de massa.

Retornando-se ao início do povoamento dos Estados Unidos, percebe-se o enraizamento deste ideal de liberdade naquela terra. Vindos principalmente de países europeus, os povoadores fugiam dos tabus culturais e morais, dos padrões judaico-cristãos, das tradições, dos preconceitos e das velhas formas de instituições sociais, como afirma Almeida (1996). Esse imaginário de liberdade foi inculcado entre os jovens.

Após a Segunda Guerra Mundial e o intenso desenvolvimento tecnológico norte americano, vê-se a perda daqueles antigos ideais de liberdade e a aridez afetual e emocional citada anteriormente. Faz-se importante afirmar que essa aridez não é ocasionada especificamente pela consolidação do capitalismo, como se as mudanças econômicas fossem as únicas responsáveis pelas mudanças na organização social. Almeida (1996) diz que a contracultura não foi propriamente um movimento anti-capitalista. Ao mesmo tempo, manifestou-se contra a cultura estabelecida, daí o nome contracultura, plantando novos ideais de viver em relação à família, ao casamento, às relações sexuais, com o corpo e com a natureza.

Os jovens desse momento gozavam de tempo livre e da não necessidade de trabalhar, fala-se aqui dos jovens de classe média, favorecidos por uma intensa aquisição de bens materiais e vivendo em uma materialidade até então desconhecida. Envolvidos na propagação da guerra fria e ainda questionando o horror da guerra, tais jovens recorrem àquele velho ideal de liberdade e começam a questionar a cultura norte americana vigente. Porém, esse questionar foi impulsionado por uma educação liberal, que estimulava a capacidade de expressão. Com isso, os jovens passaram a ser mais críticos e contestadores, exigindo soluções para os problemas que os rodeavam, sendo esta ação uma resposta ao momento em que viviam, como atesta Santos:

Não é estranho que a contracultura tenha surgido no seio da sociedade norte americana, pois é justamente aí que a tecnocrata-sociedade, gerenciada por especialistas técnicos e seus modelos científicos - atingiu o auge de seu desenvolvimento, obrigando o jovem a adaptar-se rapidamente a uma realidade mecânica, árida e desprovida de qualquer impulso criativo. Com isso, a contracultura se tornou a forma de expressão mais importante dessa parcela de jovens que procuravam "cair fora" - drop out - dos padrões estabelecidos por essa sociedade, para construir um mundo alternativo com uma "cultura” própria (2005, p.63-64). 
Rebeldes sem causa foi uma expressão muito utilizada para definir aqueles jovens norte americanos, que, através do cinema, foram propagados. "Os problemas dos jovens norte americanos passavam a ser também os problemas de jovens de outros países" (Canhête, 2004, p. 49). O resultado disso foi a criação de uma postura de confronto com o mundo adulto, surgindo um novo estilo de organização social. Com os heróis do cinema, vieram as gangs, que se contrapunham inteiramente aos modos de vida preconcebidos pelo mundo dos adultos (Canhête, 2004). Contudo, é necessário pensar em gang como uma reunião de jovens da classe média, imigrantes, com ideais de mudança, e não no sentido atual dado ao termo gang relacionado com violência, periferia e jovens pobres.

Percebia-se, naquela época, uma exaltação ao ser jovem e à conquista de um espaço na sociedade pela juventude, iniciando-se a formação dos primeiros territórios juvenis, já que, de um contexto social em que se "saltava a adolescência”, passou-se a outro no qual a adolescência era a idade favorita. Deseja-se chegar a ela cedo e nela permanecer por muito tempo, como menciona Abramo (1994), que ainda salienta o aumento da disponibilidade e da procura por diversão e por elementos diferenciados de consumo. Isso provocou rápida resposta por parte da indústria, do comércio e da publicidade, que passaram a produzir bens específicos para esse público, alimentando o espraiamento dos novos hábitos, como a locomoção por motocicleta. Morin (1986) também percebe aquela juventude como resposta ao modelo da sociedade pois, favorecida pela "relativa autonomia monetária" (conseguida com mesadas ou empregos), acede a bens e formas de lazer e torna-se contestadora e exigente de maiores liberdades.

Roszac (1972) vê o movimento de contracultura como uma oposição juvenil a essa sociedade tecnocrática, que atinge o ápice de sua integração organizacional por meio de imperativos incontestáveis como a procura de eficiência e segurança, combinados com o desejo de racionalização.

Os ideais, pensamentos e manifestações juvenis, vindos do pós-guerra, nas sociedades mais industrializadas, formaram então o Movimento de Contracultura, que foi assumido por grandes grupos que tomam proporções internacionais, como os Hippies. E como se inserem nisso as tribos urbanas? Nos movimentos de contracultura, surgiram grupos específicos denominados de tribos urbanas por autores como Zalduendo (2000), Almeida (1996), Canhête (2004), Chies (2007), Borges e Covre (2007) e Coutinho (2007).

Os grupos vindos dos movimentos de contracultura, e que atualmente são chamados de tribos urbanas, são manifestações passageiras, ou 
seja, englobam a faixa de transição para a vida adulta e esta, quando chega, força o pertencente a abandonar sua tribo, como confirma Coutinho: "a transitoriariedade e o imediatismo se congregam numa certa apologia do presente vivido na tribo, não há projetos futuros ou preocupações com o destino da tribo" $(2007,04)$. São escassos os citadinos que permanecem vivendo em tribos urbanas, neste sentido, até a "velhice", e, quando isso acontece, como é o exemplo do movimento Hippie, eles criam vivências grupais fechadas e à margem do sistema, sem grandes configurações coletivas que permitam sua visualização enquanto movimentos culturais, como as comunidades alternativas.

Acerca dos moto clubes, a partir dessas observações, é nítido que eles surgiram em meio ao movimento de contracultura nos Estados Unidos e, atualmente, são incluídos nas tribos urbanas. A seguir será apresentado um breve histórico do surgimento desses grupos, assim como uma caracterização de seus territórios e territorialidades existentes na cidade de Goiânia.

\section{A Distância Mostra Como é Bom Estarmos Juntos: tribos de moto clubes goianienses}

Em meados de 1940, surgem os primeiros Moto Clubes do mundo, exatamente nos Estados Unidos, estando dentro dos ideais que posteriormente foram chamados de contracultura. Eram formados, naquele momento, por homens jovens, mas com idade e condições financeiras para possuir uma motocicleta e dedicare-se a viagens pelas rodovias do país, sendo conhecidos nas décadas seguintes como gangues de motociclistas. Outra origem foi a dos ex-combatentes que decidiram igualmente viajar de motocicletas na tentativa de esquecer os dias vividos em guerra (2004). Percebe-se, com isso, que o veículo apresentava outro sentido, ultrapassando o de simples locomoção de pessoas, posto que associava-se também a um novo modo de vida, um novo grupo urbano, ou uma nova tribo urbana.

Os primeiros M.C. foram os Hell's Angel, Diablos, Presidents, Road Rats, Nightriders, Question Marks e Satan's Slaves (Thompson, 2004). Origina-se aí também o mito do motociclista anti-social e da motocicleta como instrumento de liberdade, protesto e irreverência. As motos vindas das duas grandes guerras e modificadas por esses motociclistas foram batizadas de Choppers, termo britânico que possui o significado de cortada, modificada. Isto consiste em aproveitar o quadro e/ou o motor da moto original, sendo 
que os demais acessórios vão sendo moldados pela arte e criatividade. O que surge nesse momento é o processo conhecido na atualidade como personalização ou customização de motocicletas. Enquanto as indústrias automobilísticas produziam automóveis confortáveis e motocicletas tecnologicamente modernas para locomoção de pessoas, esportes e longas viagens, certos motociclistas preferiam construir as suas próprias e diferenciadas motocicletas.

Com o auxílio da indústria do cinema, principalmente de Hollywood, este modo de vida (viajar em grupos de motocicleta) se propagou pelo mundo através de filmes, seriados, documentários e desenhos animados como Jaspion, Carangos e Motocas, Jiban, O vigilante rodoviário, The wild one, Rebel without a cause, Easy Rider, East of éden, Ruas de fogo, Amor a toda velocidade, Selvagem da motocicleta e Selvagens da noite.

No que se refere ao Brasil, Zardini (2007) informa que, durante a segunda guerra mundial, o país enviava alimentos para os combatentes em troca de motocicletas usadas. Fonseca (2001) complementa que, em meados de 1940, foram importadas motocicletas vindas de fábricas da Itália, Alemanha, Inglaterra e Estados Unidos para fins militares, também sendo posteriormente vendidas para uso particular e para competições. Paralelamente, importou-se o costume europeu de expor os veículos militares, em especial as motocicletas, nos festejos e desfiles cívicos.

Em Goiânia, Fonseca (2001) comenta que as primeiras motocicletas chegaram em 1942, também importadas para fins militares, sendo isto incentivado por Pedro Ludovico Teixeira (primeiro prefeito de Goiânia), que possuía fascínio por este veículo. Em 5 de julho de 1942 as motocicletas entraram nas comemorações cívicas do batismo cultural da cidade, sendo expostas nos desfiles e participando de competições.

Em 1955, surge o Moto Clube de Goiânia, com 146 sócios, e também a Federação Goiana de Motociclismo, organizações que incentivaram as competições na cidade e a construção do Autódromo Internacional de Goiânia, em 1974. Porém, ressalte-se que essas organizações nada pareciam com os atuais moto clubes existentes em Goiânia e tampouco com os gestados em solo americanos.

O primeiro moto clube de Goiânia foi o Vikings, fundado em 1986 por colecionadores de motocicletas antigas e amantes do modelo chopper. Os seus membros participaram de encontros de colecionadores pelo país e promoveram esse tipo de encontro em Goiânia também. Com esses eventos, conheceram moto clubes brasileiros com ideais e formas de organização próximas às de contracultura dos Estados Unidos, foram eles os Sarracenos, 
Balaios, Carcarás e Águias de Aço. A partir desse contato, os Vikings modificaram a estrutura de apenas colecionadores de motocicletas para se tornarem de fato moto clube. Como isso, surgiram conflitos internos no grupo e alguns membros dissidentes fundaram o Chopper, o Papa-Léguas e o Alcatéia, todos em 1994 e existentes até hoje. Juntamente com esses moto clubes, surgiram oficinas especializadas em personalização e customização, além de espaços específicos para encontros e comércio especializado em acessórios; assim como a cidade se abre para que moto clubes de outros estados fundem facções1 em Goiânia.

Atualmente, são trinta e nove M.C.s com características diferenciadas entre si. Existem os que seguem ideais daqueles gestados em solo americano, os que são compostos por elos familiares ou de amizades, além dos maçônicos, filantrópicos, religiosos (evangélicos), de distinção sexual (mulheres) e que exigem marca, modelo ou cilindrada específica da motocicleta.

Nessa re-significação do uso da motocicleta e dos moto clubes, Teixeira (2006) divide essas entidades segundo as formas de organização em Moto associações, Moto clubes familiares e Moto clubes tradicionais. As Moto associações se identificam com aquelas organizações de 1955 em Goiânia (Moto Clube de Goiânia e Federação Goiana de Motociclismo, que envolve os esportes); os familiares são grupos de amigos, pais e filhos que viajam juntos; já os tradicionais "tentam” preservar o ideal originário dos Estados Unidos e têm regras mais severas para pertencimento ao grupo.

Para apreender melhor a razão de ser desses grupos e sua apropriação do espaço urbano, utilizam-se aqui os conceitos de território e territorialidade. Sobre território, é nítido que as tribos urbanas são formadoras de territórios diferenciados na cidade. A requisição, a posse, ou o controle espacial, mesmo que temporário, expressam relações de poder intimamente ligadas às maneiras de agir sobre os outros, diferenciando quem controla e quem é controlado em um dado terreno. De outro modo, conforme observa Sack (1986), o território é formado em determinado espaço apropriado, no sentido de afetar, influenciar e impor diferentes tipos de acesso às pessoas e aos recursos.

As tribos urbanas mencionadas se expõem, em especial, no cenário noturno, e delimitam os seus territórios com a "simples" presença corporal. Naquele tempo de estadia, o seu território é fixo e diferenciado, chegando a fazer os outros mudarem a direção do caminhar para não invadi-lo. Porém, mesmo na ausência corporal, os territórios podem delimitar-se através de suas representações simbólicas, o que se considera como território invisível. 
Propõe-se então que existem territórios fixos, eventuais, visíveis e invisíveis, não se podendo relegar o fato de que há territórios em diversas escalas, podendo se estender desde um país ou bloco continental (como no caso do moto clube Hell's Angels que é internacional e o que contém mais filiados, ou como o Chopper que só existe e contém três membros) até uma quadra de bairro, ou uma mesa de bar (como acontece nos encontros esporádicos).

Na formação de territórios são tomadas iniciativas individuais ou grupais (estratégias territoriais) para delimitação e manutenção. Essas estratégias são consideradas aqui como territorialidades. De acordo com Machado (1997) a territorialidade corresponde às ações desenvolvidas por vários agentes sociais em uma determinada área geográfica e em um dado momento histórico. As ações são produzidas pelas diferentes relações estabelecidas entre os agentes em um específico recorte espaço-temporal.

Olhando-se para os moto clubes a partir desses dois conceitos (território e territolialidade), tribo urbana torna-se uma metáfora para entendê-los como associações existentes na cidade que trazem consigo inúmeras cargas comportamentais e simbólicas para marcarem a sua territorialidade no espaço urbano, muitas vezes com a "simples" presença corporal de um membro usando o colete, ou mesmo pela presença de seus símbolos identitários, motocicletas diferenciadas, faixas de segurança, bandeira do moto clube, ou cones. Foi feito um levantamento dos territórios fixos e eventuais, abrangendo o período já mencionado, e concluiu-se, que na década de 8,0 os moto clubes utilizavam espaços públicos e comerciais para se reunirem e, posteriormente, surgiram as sedes e espaços públicos cedidos pela prefeitura para promoção dos encontros, notando-se, assim, o aumento desses territórios pela cidade (Figura 1).

Esses territórios apresentados demonstram diferenças em escalas espaço-temporais, e, principalmente, na forma de manutenção, portanto, o que deve ser explicitado são as rivalidades e conflitos na ultrapassagem dessas fronteiras físicas ou invisíveis.

No moto clube, existe hierarquia de organização composta por presidente, os membros mais velhos, com o colete completo, e os membros mais novos, com o colete faltando o brasão e geralmente constando apenas com o nome do moto clube. Estes geralmente são os guardas das motocicletas em eventos, para que não roubem, não toquem, ou mesmo não tirem fotografias. Os moto clubes com sede, restringem a entrada apenas a convidados e com datas e horários específicos. No caso dos moto bares, existem aqueles cujo proprietário é membro de um moto clube, mas isto não é regra. Em sendo 
proprietário, a freqüência, no que diz respeito a integrantes de moto clubes, é exclusiva de pares, ou brothers.

Quadro 1. Territórios de moto clubes na cidade de Goiânia - Década de 80 aos anos 2000 .

\begin{tabular}{|c|c|c|}
\hline Década de 80 & Década de 90 & Anos 2000 \\
\hline $\begin{array}{l}\text { § Oficina e Residência - Antônio } \\
\text { Águia } \\
\text { § Residência Derosi } \\
\text { § Pizzaria Quadra } 100 \\
\text { § Automóvel Clube } \\
\text { § Residência Sr. Guerino } \\
\text { § Oficina - Adir } \\
\text { § Bar Circus } \\
\text { § Loja } 1000 \text { Yamaha } \\
\text { § Sede dos Vikings M.C2. } \\
\text { § Residência e oficina do Alcides } \\
\text { § Residência e Oficina do } \\
\text { Zardini } \\
\text { § Estacionamento do M.C. } \\
\text { Donalds }\end{array}$ & $\begin{array}{l}\text { § I Encontro Nacional de } \\
\text { Antigomobilismo } \\
\text { § II Encontro Nacional de } \\
\text { Antigomobilismo - Classic } \\
\text { Motor Show } \\
\text { § Zardini Super MotoShow - } \\
1994 \text { até } 2000 \\
\text { § Praça Universitária } \\
\text { § Bar Honk Tonk } \\
\text { § Avalon Boate } \\
\text { § Terceira Onda Boate } \\
\text { § Oficina e Residência - Antônio } \\
\text { Águia } \\
\text { § Gyn Moto Rock } \\
\text { § Oficina do Geraldo e Luizim } \\
\text { § Oficina Jabur } \\
\text { § Estacionamento do Girafas } \\
\text { § Sede dos Vikings } \\
\text { § Pit Dog - Dog Din } \\
\text { § Pit Dog - Afonsos Burguer } \\
\text { § Pit Dog - Jocasto } \\
\text { § Feira da Marreta } \\
\text { § Alveria Bar } \\
\text { § Shopping Bouganville } \\
\text { § Goiânia Shopping }\end{array}$ & $\begin{array}{l}\text { § Shopping Bouganville } \\
\text { § Goiânia Shopping } \\
\text { § Shopping Flamboyat } \\
\text { § Centro Cultural Oscar } \\
\text { Niemeyer } \\
\text { § Parque de Exposição } \\
\text { Agropecuária de Goiânia } \\
\text { § Rua c-30 } \\
\text { § Sede do QBU M.C. } \\
\text { § Sede do Hurricane M.C. } \\
\text { § Vai Toma no Kuka Bar } \\
\text { § Avenida Paranaíba } \\
\text { § Sede dos Muthantes M.C. } \\
\text { § Bar Muthantes M.C. } \\
\text { § Bar Dom Guina } \\
\text { § Sede do Alcatéia M.C. } \\
\text { § Bar Aro 16 } \\
\text { § Sede do Chopper M.C. } \\
\text { § Lote do Chopper M.C. } \\
\text { § Bar Taverna Vikings M.C. } \\
\text { § Posto da Rua 74 } \\
\text { § Goiânia Moto Show 2002 até } \\
\text { 2005 } \\
\text { § Bar Taba de Chiqueiro } \\
\text { § Posto T 10 } \\
\text { § Bar Torneadora Kaverna } \\
\text { § Oficina do Luizim } \\
\text { § Oficina do Geraldo } \\
\text { § Oficina do Robertão } \\
\text { § Nana Moto Elétrica } \\
\text { § Bráulio - Aerografia } \\
\text { § Jozé - Pintura } \\
\text { § Sede Prospect 81 M.C. } \\
\text { § Sede dos Forasteiros M.C. }\end{array}$ \\
\hline
\end{tabular}

Em locais públicos, como a praça da Avenida Paranaíba no centro de Goiânia, existe um encontro de moto clubes todas as quintas-feiras em período noturno. Desde 2001, quando foi cedido este espaço, cada moto clube 
tem o seu "pedaço" fixo. Então os novos moto clubes devem conversar com os mais antigos para poderem se encaixar na praça e aos poucos conquistarem o seu território.

Outra rivalidade nítida é estabelecida a partir do modelo e da cilindrada das motocicletas. As japonesas de alta velocidade são as jaspeiras, e as custom e choppers são chamadas de estradeiras. Em determinados encontros, é proibida a entrada de jaspeiros. Quanto à cilindrada, nos encontros só cobra-se a entrada de motocicletas abaixo de 250 cilindradas.

\section{No fim do caminho, o recomeço!}

Neste rápido texto, demonstrou-se como a inspiração em movimentos culturais influenciou o surgimento dos moto clubes e implicou na adoção de certos equipamentos definidores de territórios que, no caso específico de Goiânia, são moto bares, bares, praças, sedes, shows, eventos etc. alguns dos quais apropriados de modo flexível, servindo de local de passagem ou de encontros eventuais. Entretanto, não basta passar por esse lugar ou mesmo freqüentá-lo com alguma regularidade para ser do pedaço; é preciso estar situado (e ser reconhecido como tal) numa peculiar rede de relações e num sistema de hierarquia. Com isso, constroem-se códigos capazes de separar, ordenar e classificar, distinguindo os do dentro e os de fora do pedaço, bem como em que grau o brother pertence à galera dos moto clubes.

Finalizando, recorremos a Magnani (2006) que destaca que as grandes metrópoles contemporâneas não podem ser vistas simplesmente como cidades que cresceram demais e desordenadamente, potencializando fatores de desagregação. Elas também propiciaram a criação de novos padrões de troca e de espaços para a sociabilidade e para os rituais da vida pública, como é o caso dos moto clubes goianienses.

\section{Notas}

1 Quando um moto clube surge em um estado ou cidade e funda uma facção em um local diferente da sua origem.

2 Abreviatura nossa para moto clube 


\section{Referências}

ABRAMO, H. W. Cenas Juvenis. São Paulo: Página Aberta, 1994.

ALMEIDA, A. F. J. A contracultura ontem e hoje. Salvador: Ciclo de debates, 1996.

AMARAL, R. C. Povo santo, povo de festa, estudo antropológico do estilo de vida dos adeptos do candomblé paulista. São Paulo: USP, 1992.

BERTAUX, D. Individualismo e modernité. Revue Espace Temps, n. 37, Paris, 1988.

BORGES, P.; COVRE, R. A. Tribos Urbanas. Disponível em: http://www.nu-sol.org/libertarias/ libertarias-4/tribos_urbanas.htm. Acesso em 03 fev. 2007

CALIGARIS, C. Pluralismo, Multiculturalismo e Universalismo: Diferenças e Aproximações. Seminário Cultura e Tolerância, SESC Vila Mariana, nov. São Paulo, 2003.

CANHÊTE, D. L. Ecos do Subterrâneo: a questão da juventude e do movimento punk como subcultura - a década de 80. Goiânia: UFG, 2004.

CHIES, T. C. Novas formas de viver: Clubbers e Ravers. Os urbanistas. Disponível em: http:// www.aguaforte.com/antropologia/Clubbers3.html. Acesso em: 03 fev. 2007.

FONSECA, R. Motopop 2001. Goiânia: Gráfica O popular, 2001.

MACHADO, M. S. Geografia e Epistemologia: Um passeio pelos conceitos de Espaço, Território e Territorialidade. GEO UERJ, Rio de Janeiro, n.1, janeiro, 1997.

MAFFESOLI, M. O tempo das tribos. Rio de Janeiro: Forense Universitária, 2004.

MAGNANI, J. G. C. De perto e de dentro: notas para uma etnografia urbana. Revista Brasileira de Ciências Sociais, v.1, n.49, jun. 2002.

MARCUSE, H. A ideologia da Sociedade Industrial. Rio de Janeiro: Zahar, 1982.

MORIN, E. Cultura de Massas no Século XX: o espírito do tempo. vol.I. Neurose. Rio de Janeiro: Forense, 1969.

ROSZAK, T. A contracultura. Petrópolis: Vozes, 1972.

SACK, R. D. Human Territoriality: Its theory and history. Cambridge University, 1986.

SALEM, T. Filhos do milagre, Ciência Hoje, vol.5 nº 25, SBPC, 1986.

SANTOS, G. S. Movimentos Contraculturais: Mitos de uma revolta, poetas de uma revolução. Akrópolis, Umuarama, v.13, n.1, jan. 2005.

SIMMEL, G. A metrópole e a vida mental. In: VELHO, G. (Org.) O fenômeno urbano. Rio de Janeiro: Guanabara, 1987.

TAKEUTI, N. Subjetividades e vínculos sociais. In: SOUZA, I.M. Café Filosófico: filosofia, cultura, e subjetividade. Natal: EDUFRN, 2004.

TEIXEIRA, L. R. M.C.s: Parte I. Boletim Informativo Tribo do Cerrado MC. Goiânia, ano 3, 12 Ed. dez. 2005.

TEIXEIRA, L. R. M.C.s: Parte II. Boletim Informativo Tribo do Cerrado MC. Goiânia, ano 4, 12 Ed. jan. 2006. 
THOMPSON, H. S. Hell's Angels: Medo e delírio sobre duas rodas.Tradução Ludimila Hashimoto. São Paulo: Conrad, 2004.

VELHO, G. Individualismo e Cultura: Notas para uma antropologia da sociedade contemporânea, 4 ed. Rio de Janeiro:Zahar, 1997.

ZALUENDO, C. L. La pasión neotribal contemporânea. In: TROPEA, F. (Org.) Tribus Urbanas: El ânsia de identidad juvenil: Entre el culto a la imagen y la autoafirmación através da violência. Buenos Aires: Paidós, 2000.

Maria Elisabethe Alves Mesquita - Mestranda em geografia pelo IESA - UFG

Carlos Maia - Prof. Dr. do IESA - UFG

Recebido para publicação em outubro de 2007 Aceito pra publicação em novembro de 2007 